\title{
Evaluation of Antibiotics Prescriptions in the City of Vitória, ES - Brazil, and its Relation with Laboratory Diagnosis
}

\section{Elton Carvalho Costa ${ }^{1}$ and Clarisse Maximo Arpini ${ }^{2 *}$}

${ }^{1}$ Pharmaceutical, Specialist in Clinical Analyzes, Emescam, Brazil

${ }^{2}$ Microbiologist, Laboratory of General Microbiology, University of Vila Velha-UVV, Brazil

*Corresponding Author: Clarisse Maximo Arpini, Microbiologist, Laboratory of General Microbiology, University of Vila Velha-UVV, Brazil.

Received: December 13, 2017; Published: January 08, 2018

DOI: 10.31080/ASMI.2018.01.0009

\begin{abstract}
Introduction: The correct diagnostics is determinant for the success of the therapy, but if eliminate any step of investigation process, either by negligence, excess of self-assurance, due to a reduction in costs or due to lack of custom to request some laboratory examination, can cause several consequences for the patient, like error on prescription, prescription of antibiotic unnecessary, adverse effects for drug interactions and the argument of bacteria strain multi-resistant.
\end{abstract}

Objective: To carry out data collection based on analysis of prescriptions and to correlate with the request of laboratory tests for the diagnosis and prescription of antibiotics.

Material and Method: Due to this problem, 90 antimicrobial prescriptions were analyzed with information about how the diagnosis was made, whether clinical examination alone or whether laboratory tests were requested and which were performed.

Result: We found a total of $83 \%$ of prescriptions without laboratory tests, prescribed by the most diverse medical specialties.

Conclusion: The findings reinforce the need of education of health professionals for the modification of these habits.

Keywords: Clinical Analysis; Prescription; Antibiotic; Diagnosis

\section{Introduction}

The use of antibiotics by people is increasingly common, don't matter the age or social class [1]. The use of antibiotics is recommended for combat of infectious agents, limiting your growth or eliminates it, without damage the patient [2]. But your abusive use is facilitating the arising of resistant strains with clinical impacts and therapeutics [1]. Just at hospitals, $1 / 3$ of costs are with prescriptions of medications. For aggravate this situation, data's of Center for Disease Control and Prevention shows that, just in EUA, one of each three antibiotics are prescripts without need and, in most times, for treatment of viral diseases that, naturally, don't answer to this therapy, like simple flu [4]. Uncontrolled prescription and, many times, without laboratory diagnostics exposes the patient to risks of allergic reactions, severe diarrhea, including Clostridium difficile, and arising of superbacterias [4,5].

Many studies has been for elucidate the undiscriminated prescription of antibiotics: pression on the prescriber exercised of own patient; diagnostic uncertainty; lack of prescriber knowledge in diagnostic techniques; prescriber's little experience in dealing with infectious diseases; difficulty in selecting the antibiotic of choice, especially in empirical treatments [6-10].

Laboratory tests and even rapid diagnostic tests have been identified as important mechanisms to reduce the prescription of antibiotics, reducing up to $70 \%$ of prescriptions in cases of lower respiratory tract infections and up to $84 \%$ of cases of pharyngitis $[11,12]$.
In an analysis of the correlation between C-reactive protein (CRP or CRP-POC) tests and antibiotic prescribing in Slovakia, revealed a $35 \%$ savings in public spending on antibiotic therapy [13].

New rapid tests have now been developed inspired by the question of the use only of clinical diagnosis. Prilutsky., et al. [14] developed a rapid test for differentiation of bacterial viral infections by chemiluminescence with results at 5 hours and accuracy of $94.7 \%$. Was also developed a virus-induced protein-based assay called Apoptosis Inducing Tumor Necrosis Factor (TRAIL) for the differentiation of bacterial viral infections with high specificity and sensitivity with results in 2 hours $[15,16]$.

Rapid tests for fungal infections are also being developed, mainly for immunocompromised patients [17]. A study conducted by Oliveira., et al. [18] uses mass spectrometry, MALDI-TOF, for the diagnosis of Sporothrix schenckii allowing a high accuracy result in only 30 minutes.

In addition to the rapid tests, we must emphasize the importance of microbiology laboratories, which provide specific culture and antibiogram data for each patient, although they are generally used to focus or interrupt empirically initiated treatment $[3,19]$.

\section{Materials and Methods}

The present study was carried out with volunteers, who were approached at the time of purchase of antibiotics in a private establishment and, of their own free will, answered a questionnaire (Table 1) anonymously. The research was conducted over a period of 90 days. 


\begin{tabular}{|c|c|c|c|c|c|c|c|c|c|c|}
\hline & \multicolumn{3}{|c|}{ Patient } & \multirow{2}{*}{$\begin{array}{c}\text { Indication/ } \\
\text { Pathology }\end{array}$} & \multirow[t]{2}{*}{ Specialty } & \multirow[t]{2}{*}{ Medicament } & \multirow[t]{2}{*}{ Treatment } & \multicolumn{2}{|c|}{ Exam } & \multirow{2}{*}{$\begin{array}{c}\text { Type of Laboratory } \\
\text { Exam }\end{array}$} \\
\hline no & Age & $\mathbf{M}$ & $\mathbf{F}$ & & & & & Clinical & Labor & \\
\hline & & & & & & & & & & \\
\hline & & & & & & & & & & \\
\hline
\end{tabular}

Table 1: Questionnaire presented to the volunteer at the time of purchase of the antibiotic.

\section{Results}

According to the survey, almost $70 \%$ of the users of antibiotics are female (Figure 1), with the majority concentrated in the age group between 21 and 30 years old (Figure 2).

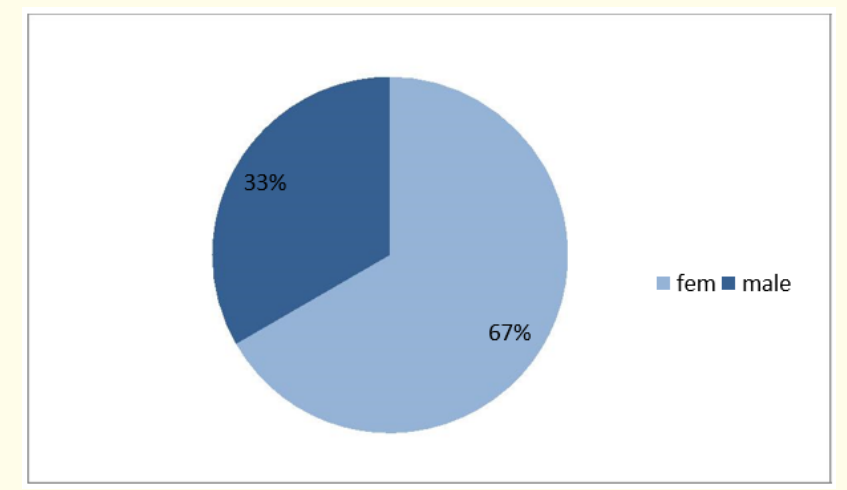

Figure 1: Chart with the consumer profile of antibiotic according to sex.

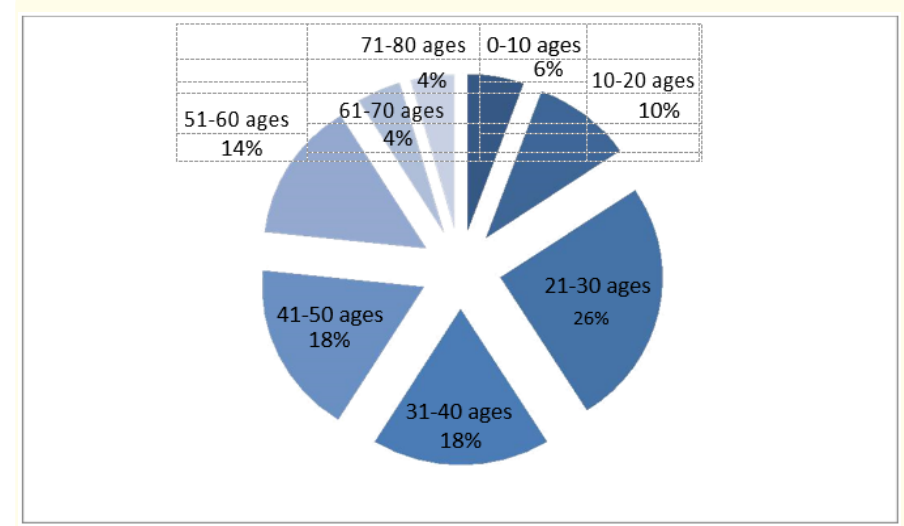

Figure 2: Profile of consumers of antibiotics according to age group.

Among the medical specialties evaluated according to the identification of the recipes presented at the time of purchase, the General Clinic (Figure 3) is the one that generated the most antibiotic revenues.

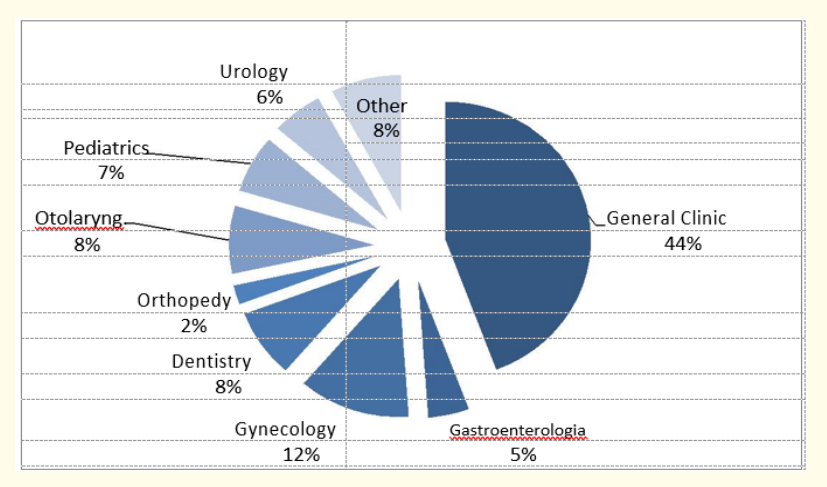

Figure 3: Percentages of medical specialties consulted according to the recipes presented at the time of purchase.
Among the complaints that generated the revenues, infections of the Genitourinary System correspond to $40 \%$, followed by Respiratory System Infections (17\%), Sinusites (17\%) and Tonsillitis (13\%).

The variety of antibiotics prescribed was very wide (Figure 4), with the most commonly prescribed classes being Penicillin, Quinolones, Macrolides and Cephalosporins.

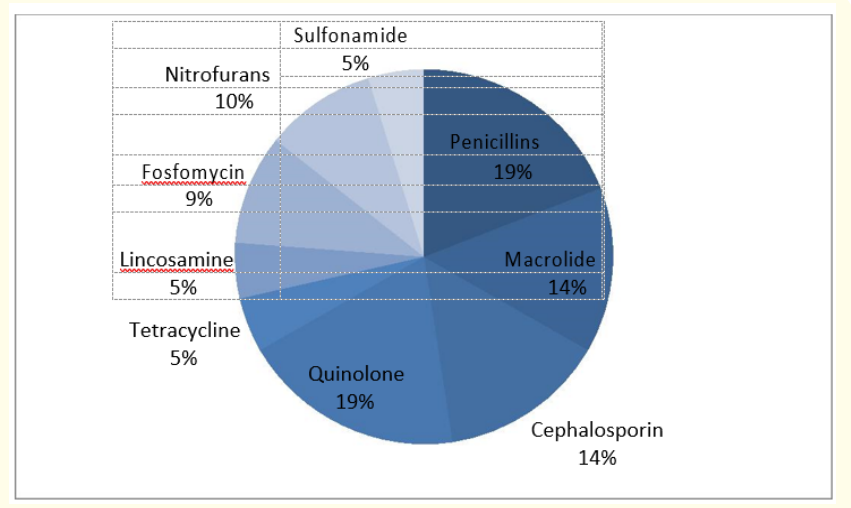

Figure 4: Frequency of classes of antibiotics prescribed.

\section{Discussion}

According to Resolution RDC No. 20/2011 of Anvisa (National Health Surveillance Agency of Brazil) [20], the supply of the prescription containing antimicrobial agents is a maximum of 10 days. Therefore, the revenues that were presented out of date were not compiled for this study, and the attempted purchase with only revenue due twice during the data collection period occurred. The fact that few overdue revenues have been presented is also described by Nascimento and Magalhães [21], who describe only $7.9 \%$ of the total revenues analyzed in their research.

In accord to reported by Nicoline., et al. [2] and Llor and Bjerrum [22], in our research we observed the high number of recipes generated by General Clinicals. This search for General Practitioners can be explained by the habit of the population often resorting to ready care on a first visit to the doctor or in search of an immediate treatment. In their studies, Nascimento and Magalhães [21] report that half of the revenues analyzed did not contain the medical specialty informed.

Llor and Bjerrum [22] report as the major causes of complaints the Respiratory Tract infections, but in our observations the main complaint was infections in the Genitourinary Apparatus. Complaints related to the Respiratory System soon followed.

In only $8 \%$ of the analyzed cases, the antibiotics were prescribed by protocol pre and post-surgical in Dentistry. In the other cases the recipes were generated according to pathological complaints, but what draws attention is the fact that in approximately $83 \%$ of cases the diagnosis and definition of treatment was made only with clinical examination. 
The most prescribed classes of antibiotics are probably due to the broad-spectrum action. This can be explained by the fact that there is a low request for laboratory tests and, among the cases in which the application was made, only at the half (50\%) the culture was requested. This means that, among the 90 cases analyzed, in less than $8 \%$ bacterial culture was requested. The bacterial cultures requested corresponded to the diagnosis of genito-urinary tract infections.

Nascimento and Magalhães [21] describe very similar results regarding the classes of antimicrobials prescribed and frequency that were prescribed. Nicoline., et al. [2] describes Penicillins being prescribed in $50 \%$ of the evaluated recipes, followed by Cephalosporins in the public network.

Mangione-Smith., et al. [6] revealed in their researches that in $62 \%$ of the cases in which the pediatrician perceived the expectation of the prescription of antibiotics by the patient's parents, he received them and, in $70 \%$ of these cases, the pediatrician was prone to diagnosis of bacterial infection. Still in this study it was revealed that the greatest factor of parents' satisfaction was due to the attendance in the office and not to the success in the treatment [6].

In one study, a comparison was made between the clinical diagnosis of streptococcal pharyngotonsillitis, culture using classical methodology and the use of rapid tests. The high number discrepancy of clinically diagnosed positive cases was clearly evidenced while the laboratory tests (culture and rapid tests) demonstrated that the number of actual positive cases was much lower. And among the laboratory tests the culture is still the most indicated [23]. Also in this study, it was demonstrated that the physician's subjective evaluation failed to identify $21 \%$ of the positive cases, besides recommending the use of antibiotics to $47 \%$ of the children with negative culture [23].

Although rapid tests, such as through protein evaluation (Procalcitonin and C-reactive protein) may present certain subjectivity and variability according to the patient, it is still a better option than only a clinical diagnosis only $[16,19,24]$.

Studies reveal the aggravating fact that the patient often does not have a good understanding of how to use the antibiotic and its risks, emphasizing the importance of the presence of the pharmacist at the time of dispensing [2,25]. Conceição and Morais [1], in their work, show that after interviewing 56 people, they found that only one of them turned to the pharmacist for guidance on drug interactions.

Llor and Bjerrum [22] suggest, in order to reduce the excessive prescription of antibiotics, multifaceted actions, that is, the use of antimicrobial administration programs, associated with the promotion of prescription strategies, use of laboratory tests or rapid tests, and patient awareness by direct approaches and leaflets.

\section{Conclusions}

It can be inferred through the analysis of the results that there is a culture in making a diagnosis and definition of treatment protocols without any investigation through laboratory tests, either through rapid tests or through more accurate tests. The danger of this habit is the error of the diagnosis with consequent treatment error, with possible adverse reactions, drug interactions and the emergence of multi-resistant bacterial strains. There is a need to implement the habit of requesting complementary tests, either through classic methodology or rapid tests, because in addition to increasing the safety of the diagnosis and, consequently, of the treatment there is also the financial influence whether in the hospital, private or public sphere, or directly on the patient.

All these results corroborate what Xavier and Barros [26] have cited about despite the saying that the clinic is sovereign, currently the information provided by the clinical laboratory has never been so important in the diagnosis and treatment decisions.

\section{Bibliography}

1. Conceição S and Morais DCM. "Automedicação com antibióticos em estabelecimentos farmacêutico do município de Mogi Mirim, SP, Brasil". Foco 3.3 (2012): 23-33.

2. Nicoline P., et al. "Fatores relacionados à prescrição médica de antibióticos em farmácia pública da região oeste da cidade de São Paulo". Ciências Saúde Coletiva 13.4-5 (2008): 689-696.

3. Silva EU. "A importância do controle da prescrição de antimicrobianos em hospitais para a melhoria da qualidade, redução dos custos e controle da resistência bacteriana". Prática Hospitalar 57 (2008): 101-106.

4. CDC - Center for Desease Control and Prevetion. "1 in 3 antibiotic prescriptions unnecessary". (2017).

5. Streit S., et al. "Clinical and haematological preictors of antibiotic prescribing for acute cough in adults in Swiss practices - na observational study". BCM Family Practice 16 (2015): 15.

6. Mangione-Smith R., et al. "The Relationship Between Perceived Parental Expectations and Pediatrician Antimicrobial Prescribing Behavior". Pediatrics 103.4 (1999): 711-718.

7. Gaur AH and English BK. "The judicious use of antibiotics - An investment towards optimised health care". Indian Journal of Pediatrics 73.4 (2006): 343-350.

8. Bisht., et al. "Antibiotic resistance - A global issue of concern". Asian Journal of Pharmaceutical and Clinical Research 2.2 (2009): 34-39.

9. Colgan R and Powers JH. "Appropriate Antimicrobial Prescribing: Approaches that Limit Antibiotic Resistance". American Family Physician 64.6 (2001): 999-1004.

10. Adorka M., et al. "Healthcare providers' attitudes and perceptions in infection diagnosis and antibiotic prescribing in public health institutions in Lesotho: a cross sectional survey". African Health Sciences 13.2 (2013): 344-350.

11. Llor C., et al. "Recomendaciones de utilización de técnicas de diagnóstico rápido en infecciones respiratorias em atención primaria”. Aten Primaria 49.7 (2017): 426-437.

12. Llor C., et al. "Estimated saving of antibiotics in pharyngitis and lower respiratory tract infections if general practitioners used rapid tests and followed guidelines". Aten Primaria 49.6 (2017):319-325.

13. Haramiova Z., et al. "Economic Consequences of The Determinalistic Relation Between Laboratory Tests Indication and Antibiotic Prescription". Value in Health 19.7 (2016): A347A766.

14. Prilutsky D., et al. "Differentiation between Viral and Bacte- 
rial Acute Infections Using Chemiluminescent Signatures of Circulating Phagocytes". Analytical Chemistry 83.11 (2011): 4258-4265.

15. Oved K., et al. "A Novel Host-Proteome Signature for Distinguishing between Acute Bacterial and Viral Infections". PLoS ONE 10.3 (2015): e0120012.

16. Srugo I., et al. "Validation of a Novel Assay to Distinguish Bacterial and Viral Infections". Pediatrics 140.4 (2017): e20163453.

17. Guimarães AJ., et al. "Diagnosis of histoplasmosis". Brazilian Journal of Microbiology 37.1 (2006): 1-13.

18. Oliveira MME., et al. "Development and optimization of a new MALDI-TOF protocol for identification of the Sporothrix species complex". Research in Microbiology 166.2 (2015): 102-110.

19. Boyles TH and Wasserman S. "Diagnosis of bacterial infection". South African Medical Journal 105.5 (2015): 419.

20. Anvisa - Agência Nacional de Vigilância Sanitária. ResoluçãoRDC № 20, de 5 de maio de (2011).

21. Nascimento PS and Magalhães IRS. "Análise da prescrição de antimicrobianos dispensados em uma rede de drogarias da região Norte do Brasil". Revista Brasileira de Ciências Farmacêuticas 94.3 (2013): 211-218.

22. Llor C and Bjerrum L. "Antimicrobial resistance: risk associated with antibiotic overuse and initiatives to reduce the problem". Therapeutic Advances in Drug Safety 5.6 (2014) 229-241.

23. dos Santos., et al. "Comparação entre métodos clínicos e laboratoriaisno diagnóstico das faringotonsilites estreptocócicas". Journal of Pediatrics 81.1 (2005): 23-28.

24. Van den Brue A., et al. "Diagnostic value of laboratory tests in identifying serious infections in febrile children: systematic review". British Medical Journal 342 (2011): d3082.

25. Akici A., et al. "Precribing of general practtioners in the treatment of childhood respiratory-tract infections". European Journal of Clinical Pharmacology 60 (2004): 211-216.

26. Xavier RM and Barros E. "O medico e o laboratório". In: Barros E, Albuquerque GC, Xavier RM. Laboratório na prática clínica - consulta rápida - Porto Alegre: Artmed. 3o edition (2016): $1-12$.

Volume 1 Issue 2 February 2018

(C) All rights are reserved by Elton Carvalho Costa and Clarisse Maximo Arpini. 